\title{
PENGARUH METODE CERAMAH DAN DISKUSI TERHADAP PENGETAHUAN DAN SIKAP IBU HAMIL TENTANG PENCEGAHAN MAKROSOMIA DI PUSKESMAS SIABU KABUPATEN MANDAILING NATAL TAHUN 2016
}

\author{
Rizki Noviyanti \\ STIKes Rumah Sakit Haji Medan, Indonesia
}

\begin{abstract}
Article Info
ABSTRACT

Counseling is one of the methods to forestall macrosomia. It play an important role in providing knowledge for pregnant women about macrosomia so that in the future pregnant women can know and act in a certain way to forestall the incidence of macrosomia during pregnancy. The objective of the research was to find out the influence of lecture and discussion methods on pregnant women's knowledge and attitude toward forestalling macrosomia at Siabu Puskesmas, Mandailing Natal Regency, in 2016. The research used quasi experimental method with pretest-posttest design. 15 respondents were in lecture method group and 15 respondents were in discussion method group. The data were analyzed by using statistic t-independent test at $\alpha=5 \%$. The result of the research showed that there was the influence of lecture and discussion methods on pregnant women's knowledge of macrosomia. The change in knowledge was bigger in using discussion method at the mean value of4.33 than lecture method at mea value of 3.58 so that discussion method was more effective in pregnant women's knowledge of macrosomia that that in lecture method. There was the influence of lecture and discussion methods on pregnant women's attitude toward macrosomia. The change in attitude was bigger in using discussion method at mean value of 13.20 than that in lecture method at mean value of 8.62 so that discussion method was more effective in pregnant women's attitude toward macrosomia than that in lecture method. It is recommended that the management of Puskesmas increase people's participation in pregnant women's health by providing health counseling about forestalling macrosomia so that they will know the complication caused by macrosomia and how to forestall it. This health education is also an attempt to improve preventive service in health.
\end{abstract}

This is an open access article under the CC BY-SAlicense.

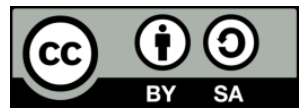

\section{Corresponding Author:}

Rizki Noviyanti,

Program Studi D-III Kebidanan,

STIKes Rumah Sakit Haji Medan,

Jl. Rumah Sakit H., Medan Estate, Kec. Percut Sei Tuan, Kabupaten Deli Serdang, Medan-Sumatera Utara. Email: kikiharahap91@gmail.com 


\section{INTRODUCTION}

Makrosomia adalah bayi yang lahir dengan berat badan lebih dari 4000 gram. Saat lahir, bayi yang besar masa kehamilan secara khas memiliki wajah yang kerubi (seperti tomat atau cushingoid), badan montok, bengkak, kemerahan, dan kulit bercorak (Bobak, 2005). Makrosomia juga sering disebut dengan giant baby atau bayi raksasa. Kemunculan bayi-bayi seperti ini disebabkan oleh beberapa faktor. Pertama, orangtuanya memang besar. Kedua, faktor ibu hamil yang menderita diabetes milletus. Ketiga, faktor ibu yang mengalami kelebihan berat badan pada saat hamil dan terakhir faktor ibu yang mengalami kehamilan lewat waktu (Rukiyah, 2010).

Berdasarkan WHO, diseluruh dunia terdapat kematian ibu sebesar 500.000 jiwa pertahun dan kematian bayi khususnya neonates sebesar 10.000.000 jiwa pertahun. Di Indonesia, menurut Survei Demografi Kesehatan Indonesia (SDKI) tahun 2009 mengungkapkan rata-rata pertahun terdapat 401bayi di Indonesia yang meninggal dunia sebelum umurnya mencapai 1 tahun. Bila dirinci terdapat 157.000 bayi meninggal dunia per tahun, atau 430 bayi per hari. Penyebab kematian terbanyak disebabkan oleh sepsis (infeksi sistemik), kelainan bawaan, dan infeksi saluran pernapasan akut (Riset Kesehatan Dasar Depkes, 2007).

Makrosomia terjadi lebih dari 10\% dari seluruh kehamilan di Amerika Serikat. Pada tahun 2005 bayi dilahirkan di Brasil dengan berat 7,7kg. Di Siberia pernah dilahirkan bayi perempuan dengan berat 7,8kg pada tahun 2007. Di Indonesia, Madura juga pernah dilahirkan bayi laki-laki dengan berat 6kg pada tahun 2009. Sedangkan di Provinsi Sumatera Utara Kabupaten Batubara bayi terberat pernah dilahirkan oleh seorangi buyang berumur 41 tahun pada tahun 2009 dengan berat mencapai $8,7 \mathrm{~kg}$.

Berdasarkan survey awal yang peneliti lakukan di bulan Januari 2016, peneliti melakukan wawancara pada 7orang ibu hamil, 5 diantaranya tidak mengetahui tentang makrosomia, mereka tidak dapat menjawab pertanyaan yang peneliti ajukan mengenai pengetahuan dasar tentang pencegahan makrosomia. Sedangkan 2 diantaranya mengetahui tentang pencegahan makrosomia, mereka dapat menjawab pertanyaan yang peneliti ajukan mengenai definisi dan penyebab makrosomia.

Permasalahan pada penelitian ini adalah bagaimana pengaruh metode ceramah dan diskusi terhadap pengetahuan dan sikap ibu hamil tentang pencegahan makrosomia di Puskesmas Siabu Kabupaten Mandailing Natal Tahun 2016. Tujuan penelitian ini untuk mengetahui pengaruh metode ceramah dan diskusi terhadap pengetahuan dan sikap ibu hamil tentang pencegahan makrosomia di Puskesmas Siabu Kabupaten Mandailing Natal Tahun 2016.

\section{RESEARCH METHOD}

Jenis penelitian ini adalah quasi-Eksperimen dengan pendekatan rancangan pre test dan post test design. Penelitian dilakukan di Puskesmas Siabu dari bulan Januari sampai dengan Juni 2016. Populasi dalam penelitian ini adalah seluruh ibu hamil yang berada diseluruh desa yang ada diwilayah kerja puskesmas Siabu Kabupaten Mandailing Natal yang berjumlah 128 orang.

Metode pengambilan Sampel dalam penelitian ini adalah Tekhnik porpusive Sampling yaitu pengambilan sampel dengan pertimbangan-pertimbangan tertentu di dalam pengambilan sampelnya atau penentuan sampel sesuai dengan tujuan dan kriteria penelitian, maka didapatlah sampel 30 orang ibu hamil, 15 orang untuk kelompok metode ceramah dan 15 orang untuk kelompok metode diskusi.

Data primer diperoleh secara langsung dari responden melalui pengisian kuesioner yang diisi secara langsung oleh responden. Sebelumnya kuesioner telah diuji coba pada populasi yang memiliki kriteria yang sama ditempat yang berbeda. Data sekunder diperoleh dari data Puskesmas Siabu Tahun2016. Analisis data menggunakan analisis univariat, bivariat dengan uji T-Independent test karena data berdistribusi normal.

\section{RESULTS AND ANALYSIS}

\section{Distribusi Frekuensi Karakteristik Responden}

Hasil penelitian menunjukkan karakteristik Siabu hamil pada kelompok metode ceramah dan metode diskusi didapatkan pada metode ceramah umur ibu lebih banyak 26-30 tahun yaitu 9 orang $(60,0 \%)$ sedangkan pada metode diskusi umur 26-30 tahun yaitu 8 orang (53,3\%). Pendidikan ibu hamil lebih banyak SMA baik pada metode ceramah maupun diskusi yaitu 11 orang (73,3\%) dan 13 orang (86,6\%). Untuk metode ceramah dan diskusi pekerjaan ibu hamil yang lebih banyak sebagai Wiraswasta yaitu 8 orang $(53,3 \%)$ dan 12 orang $(80,0 \%)$.

\section{Distribusi Frekuensi Pengetahuan Responden Sebelum Dan Sesudah Metode Ceramah}

Berdasarkan penelitian menunjukkan bahwa sebelum dilakukan penyuluhan kesehatan melalui metode ceramah pertanyaan yang paling banyak dijawab salah adalah pengertian bayi makrosomia (pertanyaan nomor 2 ) sebanyak 13 orang $(86,7 \%)$. Salah satu upaya yang dilakukan ibu untuk menjaga berat badannya selama hamil (pertanyaan nomor 8) sebanyak 13 orang $(86,7 \%)$. Pengertian berat badan bayi 
normal (pertanyaan nomor 1) sebanyak 11 orang (73,3\%) dan Yang bukan upaya untuk mencegah makrosomia (bayi besar) (pertanyaan nomor 9) sebanyak 11 orang (73,3\%). Namun, sesudah dilakukan penyuluhan kesehatan melalui metode ceramah maka yang banyak dijawab benar oleh ibu hamil adalah Pengertian bayi makrosomia (pertanyaan nomor 2) sebanyak 15 orang (100\%) dan Pengertian berat badan bayi normal (pertanyaan nomor 1) sebanyak 14 orang $(93,3 \%)$.

\section{Distribusi Frekuensi Pengetahuan Responden Sebelum Dan Sesudah Metodediskusi}

Berdasarkan hasil penelitian menunjukkan bahwa sebelum dilakukan penyuluhan kesehatan melalui metode diskusi pertanyaan yang paling banyak dijawab salah adalah salahs atu upaya yang dilakukan ibu untuk menjaga berat badannya selama hamil (pertanyaan nomor 8) sebanyak 12 orang (80\%). Pengertian bayi makrosomia (pertanyaan nomor 2) sebanyak 11 orang $(73,3 \%)$. Yang bukan upaya untuk mencegah makrosomia (bayi besar) (pertanyaan nomor 9) sebanyak 11 orang $(73,3 \%)$ dan salah satu karakteristik (ciriciri) bayi makrosomia (bayi besar) (pertanyaan nomor 5) sebanyak 10 orang $(66,7 \%)$. Namun, sesudah dilakukan penyuluhan kesehatan melalui metode diskusi maka yang banyak dijawab benar oleh ibu hamil adalah Pengertian bayi makrosomia (pertanyaan nomor2) sebanyak 15 orang (100\%), Pengertian berat badan bayi normal (pertanyaan nomor 1) sebanyak 15 orang (100\%) dan Yang bukan upaya untuk mencegah makrosomia (pertanyaan nomor 9) sebanyak 15 orang $(100 \%)$.

\section{Distribusi Frekuensi Sikap Responden Sebelum Dan Sesudah Metode Ceramah}

Berdasarkan hasil penelitian bahwa pernyataan sikap yang paling banyak menjawab peningkatan sesudah dilakukan penyuluhan kesehatan melalui metode ceramah menjadi $100 \%$ adalah Pemeriksaan kehamilan secara teratur dapat mendeteksi terjadinya makrosomia (bayi besar) (pernyataan nomor 1). Ibu tidak perlu mengatur pola makan agar kenaikan berat badan dalam kehamilan tidak berlebihan (pernyataan nomor 4). Olahraga yang dilakukan ibu hamil harus sesuai keadaan dan keinginan ibu hamil agar dapat dinikmati sehingga dapat dilakukan secara teratur (pernyataan nomor11). Ibu hamil harus minum air putih minimal 8 gelas perhari (pernyataan nomor 12) dan Ibu perlu menyediakan berbagai buah atau sayuran untukd ijadikan sebagai makanan selingan (pernyataan nomor 13).

\section{Pengaruh Penyuluhan Dengan Metode Ceramah Dan Metode Diskusi Terhadap Pengetahuan Ibu Hamil Sebelum dan Sesudah Tentang Makrosomia}

Terdapat perbedaan perubahan rata-rata skor pengetahuan tentang pencegahan makrosomia antara metode ceramah dengan metode diskusi $(\mathrm{p}=0,044)$. Perubahan pengetahuan lebih besar menggunakan metode diskusi dengan nilai rata-rata 4,33 dan standar deviasi 1,231 dibanding metode ceramah dengan nilai ratarata 3,58 dan standar deviasi1,488, sehingga metode diskusi lebih berpengaruh terhadap peningkatan pengetahuan ibu hamil tentang pencegahan makrosomia dibanding metode ceramah.

Hasil penelitian ini sejalan dengan penelitian Andriyani (2009) bahwa terdapat perubahan nilai ratarata pengetahuan anak SMP tentang TB Paru pre test dan post test dengan metode ceramah yaitu dari 6,03 menjadi 10,25. Hasil uji pair-t test diperoleh nilai $\mathrm{p}<0,001$, artinya secara statistic menunjukkan terdapat pengaruh metode ceramah terhadap pengetahuan responden tentang TB Paru.

Salah satu upaya untuk meningkatkan pengetahuan ibu hamil adalah melalui pencegahan makrosomia dengan metode ceramah. Promosi Kesehatan dilingkungan sekitar berupa penyuluhan dengan metode dan media promosi yang tepat dalam pelaksanaan dan penyerapannya merupakan langkah yang strategis dalam upaya peningkatan derajat kesehatan masyarakat. Hal ini didasari pemikiran bahwa ibu- ibu dapat membagikan kembali ilmunya kepada masyarakat yang lebih luas. Pada akhirnya ibu hamil ini akan menjadi agen kesehatan yang akan bersosialisasi kepada banyak orang, sehingga promosi ini tidak hanya bagi diri sendiri, tetapi nantinya akan berguna bagi orang lain, khususnya para ibu hamil.

Berdasarkan penelitian yang dikemukakan Rudolf (2006). Kelahiran bayi besar ini menimbulkan komplikasi dalam persalinan, apalagi jika melahirkan tidak dirumah sakit. Kemungkinan bayi akan lahir dengan gangguan nafas dan kadang kala bayi lahir dengan trauma tulang leher dan bahu. Serta kemungkinan harus melahirkan lewat operasi seksio caesar. Semuanya ini terjadi akibat massa bayi yang besar sehingga tidak mungkin atau sangat sulit melewati panggul ibu. Bayi yang lahir dengan berat badan lebih dari 4000 gram berpotensi mengalami obesitas setelah dewasa. Obesitas dapat mengakibatkan berbagai penyakit diantaranya penyakit jantung dan stroke. Oleh sebab itu, diharapkan berat badan ibu selama hamil dalam batasan normal sehingga berat badan bayi ketika lahir juga dalam kisaran normal.

\section{Pengaruh Penyuluhan Dengan Metode Ceramah Dan Metode Diskusi Terhadap Sikap Ibu Hamil Sebelum Dan Sesudah Tentang Makrosomia}

Terdapat perbedaan perubahan rata-rata skor sikap tentang pencegahan makrosomia antara metode ceramah dengan diskusi $(\mathrm{p}<0,001)$.Perubahan sikap lebih besar menggunakan metode diskusi dengan 
nilairata-rata 13,20 dan standar deviasi 4,303 dibanding metode ceramah dengan nilai rata- rata 8,62 dan standar deviasi 4,615, sehingga metode diskusi lebih berpengaruh terhadap peningkatan sikap ibu hami ltentang pencegahan makrosomia dibanding metode ceramah.

Hal ini sejalan dengan penelitian oleh Sari (2007) bahwa terjadi peningkatan pengetahuan dan sikap ibu hamil tentang inisiasi menyusui dini setelah mendapatkan penyuluhan dengan metode ceramah dan leaflet maupun diskusi.

Upaya peningkatan sikap dari para ibu hamil dalam pencegahan makrosomia perlu dilakukan salah satu dengan cara metode ceramah dan metode diskusi. Kegiatan ini menjadi penting karena pemberian informasi yang terus menerus dalam skala yang luas akan meningkatkan kesadaran dalam meningkatkan kesehatan diri. Pemberian informasi dalam bentuk ceramahdan metode diskusi ternyata mampu meningkatkan pengetahuan ibu hamil yang berdampak positif terhadap sikap yang terbentuk. Perubahan sikap dipengaruhi oleh faktor pengetahuan dan kepercayaan yang didapatkan dari hasil penginderaan, salah satunya didapatkan pada pendidikan dan proses belajar. Sikap yang didasari oleh pengetahuan akan lebih langgeng daripada sikap yang tidak didasari pengetahuan.

Melihat hasil yang diperoleh bahwa dengan bantuan metode diskusi dan metode ceramah mampu menambah pengetahuan dan mampu mengubah sikap/persepsi ibu hamil mengenai makrosomia, hal ini menandakan telah terjadi dampak positif bagi ibu hamil agar mau dan mampu bertanggung jawab terhadap kesehatan dan juga dapat menyalurkan ataupun menstransfer informasi ke banyak orang, sehingga kegiatan pembelajaran yang berhubungan dengan kesehatan sebaiknya dapat dilaksanakan secara berkelanjutan.

Berdasarkan hasil penelitian ini, asumsi peneliti bahwa meningkatnya sikap responden tentang makrosomia pada kedua kelompok adalah jugad ipengaruhi proses penyuluhan melalui metode ceramah dan metode diskusi. Hal ini sesuai dengan pendapat Azwar (2013) yang menyatakan bahwa pelatihan pendidikan dan penyuluhan dapat meningkatkan nilai sikap. Melalui pendidikan kesehatan juga akan terjadi komunikasi, baik antara fasilitator dengan peserta, maupun antara peserta dengan peserta.

Tabel 1.Pengaruh Penyuluhan Melalui Metode Ceramah Dan Metode Diskusi Terhadap Pengetahuan Sikap Ibu Hamil

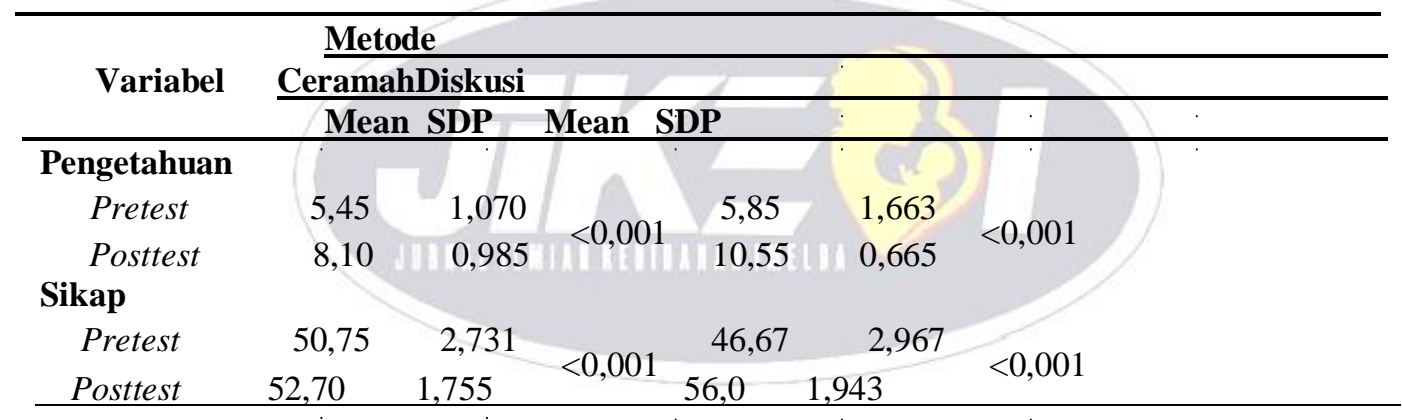

Tabel 2.Hasil Uji Normalitas Data Variabel Pengetahuan dan Sikap

\begin{tabular}{|c|c|c|c|}
\hline Variabel & $\mathbf{P}$ & Keterangan & -Uji \\
\hline$\Delta$ Pengetahuan & 0,063 & Normal & T-Independen \\
\hline$\Delta$ Sikap & 0,482 & Normal & T-Independen \\
\hline
\end{tabular}

Berdasarkan Tabel 2 menunjukkan bahwa perubahan pengetahuan dan sikap dengan uji Kolmogrov smirnov karena sampel sebanyak 30 orang diperoleh bahwa perubahan pengetahuan dan sikap berdistribusi normal $(\mathrm{p}>0,05)$.

\section{CONCLUSION}

Dapat disimpulkan bahwa Terdapat perbedaan perubahan pengetahuan dan sikap tentang makrosomia setelah mendapat penyuluhan melalui metode ceramah dengan metode diskusi. Perubahan pengetahuan dan sikap lebih besar menggunakan metode diskusi dibanding metode ceramah. Dengan kata lain, penyuluhan melalui metode diskusi lebih efektif dibanding metode ceramah karena diskusi memiliki kelebihan yaitu pesan yang disampaikan dalam bentuk kelompok dan interaksi, sehingga pesan lebih jelas danl ebih mempermudah pemahaman dan meningkatkan gairah belajar. Dengan kata lain, penyuluhan melalui metode diskusi lebih efektif dibanding metode ceramah karena pesan pada metode ceramah dapat berpengaruh secara signifikan terhadap perasaan, emosi, tingkat penerimaan atau penolakan terhadap informasi yang diberikan. 
Diharapkan kepada tenaga kesehatan Puskesmas Siabu untuk meningkatkan pembinaan peran serta masyarakat dibidang kesehatan ibu hamil khusunya memberikan penyuluhan kesehatan tentang penyebab terjadinya makrosomia dan upaya pencegahan makrosomia agar masyarakat mengetahui komplikasi yang diakibatkan makrosomia dan cara mencegah makrosomia, dan penyuluhan kesehatan ini juga merupakan upaya dalam meningkatkan kesehatan pelayanan preventif.

\section{REFERENCES}

Andriyani, S. 2009. Pengaruh Metode Ceramah pengaruh metode ceramah terhadap pengetahuan anak SMP tentang TB Paru. Berita Kedokteran Masyarakat.Vol.25.No. 3, September 2009. Hal: 133-141.

Bobak., e tal. 2005. Keperawatan Maternitas, Jakarta: EGC Depkes RI, 2003. Panduan Penggunaan Media Penyuluhan. Direktorat Jenderal PPM \&PL. Jakarta.

Hidayat, A. A. 2007. Metode Penelititan Kebidanandan Tehnik Analisa Data, Jakarta: Salemba Medika.

dayat, A.A. 2010. Metode Penelititan Kebidanandan Tehnik Analisa Data, Cetajan Keempat, Jakarta: Salemba Medika

Lina, 2012. Pengaruh Penyuluhan Kesehatan dengan Metode Ceramah dan Poster tentang Kesehatan Reproduksi terhadap Peningkatan Pengetahuan dan Sikap Remaja di SLTP Negeri 1 Siborongborong Kabupaten Tapanuli Utara tahun 2012. Skripsi FKM-USU. Medan

Notoadmojo, Soekidjo. 2010. Metodologi Penelitian Kesehatan, Edisi 3, Jakarta: RinekaCipta.

Rukiyah, A. 2010. Asuhan Kebidanan 4 (patologi), Jakarta: Trans Info Media.

Rudolph, M. 2006. Buku Ajar Pediatri Rudolph, Volume 1, Jakarta: EGC.

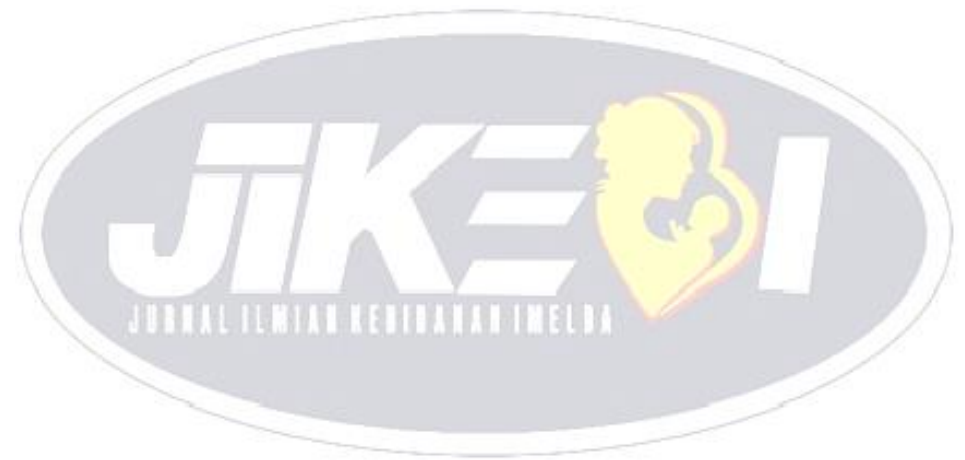

